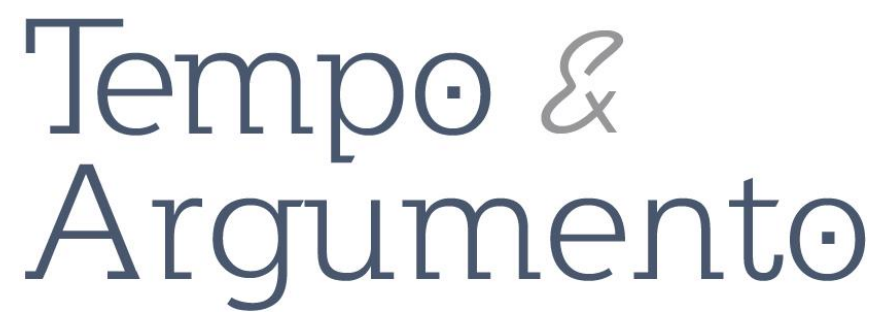

\title{
A suástica sobre o Brasil
}

Resenha da obra:

CARVALHO, Bruno Leal Pastor de; LUCAS, Taís Campelo (orgs.). Expressões do Nazismo no Brasil: partido, ideias, práticas e reflexos. Salvador: Saga, 2018, 220 p.

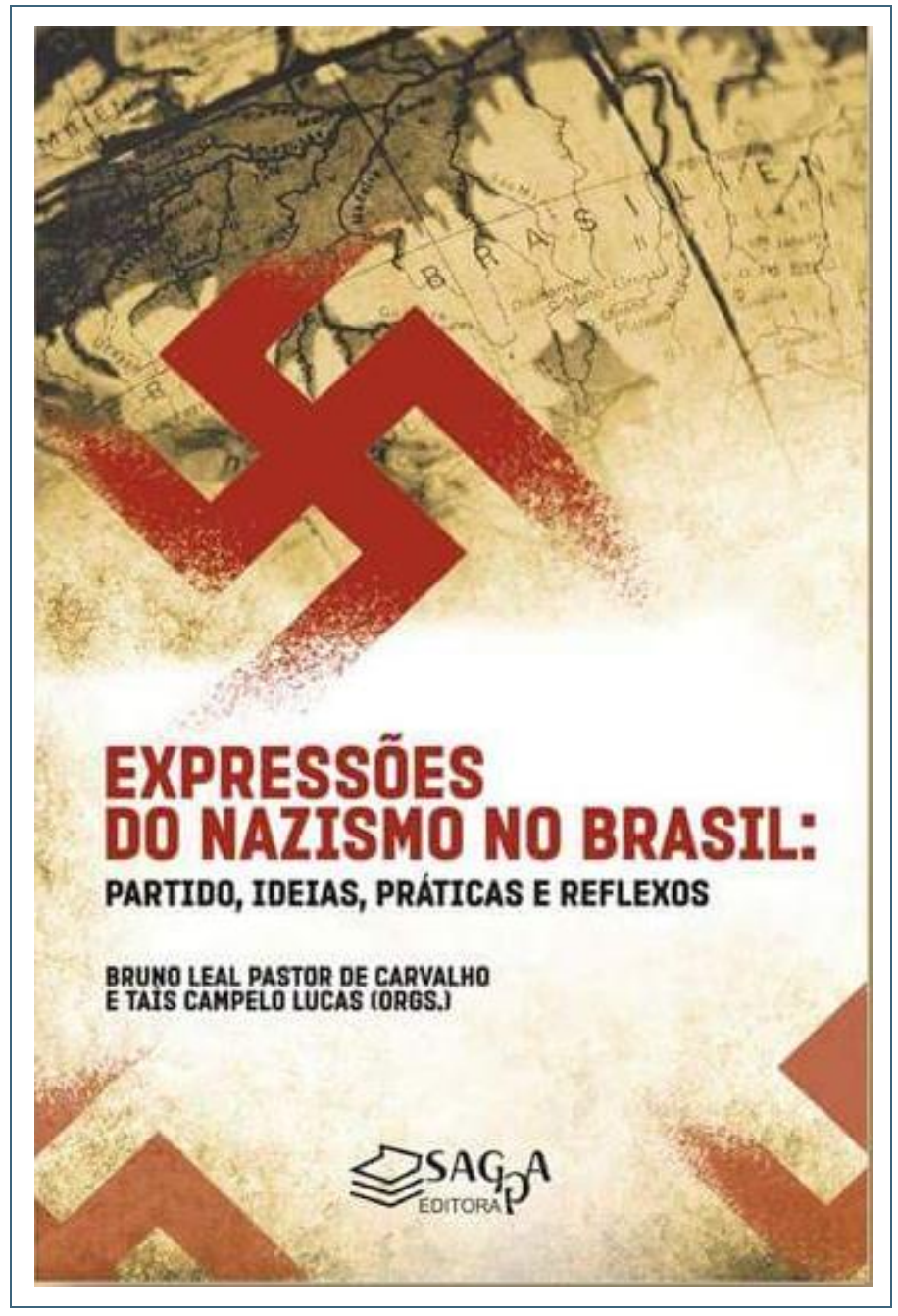

Autor da resenha

\section{Wilson de Oliveira Neto}

Doutorando em Comunicação e

Cultura na Universidade Federal do Rio de Janeiro (UFRJ). Professor da

Universidade da Região de Joinville (Univille).

Joinville, SC - BRASIL

orcid.org/0000-0002-6439-661X

wilson.o@univille.br

\section{Para citar esta resenha:}

CARVALHO, Bruno Leal Pastor de; LUCAS, Taís Campelo (orgs.). Expressões do Nazismo no Brasil: partido, ideias, práticas e reflexos. Salvador: Saga, 2018, 220 p. Resenha de: OLIVEIRA NETO, Wilson de. A suástica sobre o Brasil. Revista Tempo e Argumento, Florianópolis, v. 11, n. 27, p. 517 - 522. maio/ago. 2019. 
"O debate acerca do estatuto da Segunda Guerra Mundial no campo historiográfico tem se mostrado incessante e com bastante abertura tanto no âmbito teórico quanto metodológico", afirmou Karl Schurster (2015, p. 257), em uma resenha a respeito de um livro sobre a propaganda antissemita nazista durante a Segunda Guerra Mundial (1939-1945).

Quatro anos após sua publicação, a citação continua válida, pois, o Nazismo e a Segunda Guerra Mundial continuam a ser temas estudados por pesquisadores brasileiros e estrangeiros, dentro e fora da universidade, por meio de diferentes fontes e métodos, com resultados variados, a exemplo dos trabalhos recentes produzidos por Denise Rollemberg (2017) e Richard J. Evans (2018).

O livro Expressões do Nazismo no Brasil reforça essa tendência de renovação dos estudos históricos sobre o Nazismo, pois reúne trabalhos inéditos acerca da experiência nacional-socialista no país, a partir de recortes temáticos inéditos, a exemplo das interferências da ideologia nazista na escolha e no envio de professores universitários alemães ao Brasil, ou, de fontes primárias e secundárias consultadas em arquivos e bibliotecas alemãs, tais como os documentos relativos à Organização para o Exterior do partido nazista.

A obra é formada por nove capítulos, assinados por Luis Edmundo de Souza Moraes, Taís Campelo Lucas, Rafael Athaides, Vinícius Liebel, Priscila Perazzo, Mariana Lins Prado, Sergio Luiz Marlow, Igor Gak, Bruno Leal Pastor de Carvalho e René Gertz. Os capítulos foram divididos em três partes que conferem coerência e coesão aos textos, respectivamente: “O Partido"; “Ideias e Práticas”; “Reflexos”. Há também uma apresentação redigida pelos organizadores e um prefácio de João Fábio Bertonha, segundo o qual a experiência histórica nazista continua a ser um tema atraente para a indústria cultural, além dos seus usos políticos ao longo do tempo. Ainda no prefácio, foi destacada a relevância dos trabalhos nacionais e a necessidade de sua internacionalização.

As origens dos estudos sobre o Nazismo no Brasil estão situadas nas décadas de 1970 e 1980. Com a liberação de arquivos nacionais e alemães, a partir do fim de década de 1990, a exemplo do material do extinto Departamento de Ordem Política e Social do 
Estado de São Paulo, o tema ganhou novo impulso, o que permitiu a revisão e ampliação da bibliografia produzida, além da formulação de novos problemas de pesquisa, como por exemplo, a complexa relação entre o governo alemão e os núcleos do NSDAP no Brasil.

No capítulo de abertura, Luis Edmundo de Souza Moraes explica que as atividades do Partido Nacional-Socialista dos Trabalhadores Alemães ${ }^{1}$ no exterior foram orientadas pela Auslandorganisation - AO, a organização do NSDAP para os cidadãos alemães residentes no estrangeiro. As origens da $A O$ estão situadas em 1931, quando o líder nazista Gregor Strasser criou o Departamento para o Exterior do NSDAP, sob a direção do então deputado Hans Nieland. Em fevereiro de 1934, após avanços e retrocessos, a organização foi consolidada através do status de Gau, além de receber a denominação pela qual ficou historicamente conhecida, informa Moraes.

Em seguida, Taís Campelo Lucas narra a trajetória do Landesgruppe Brasilien, a maior seção partidária do NSDAP no exterior, com 2.903 membros registrados, além de ser o Landesgruppe mais antigo, que funcionou entre os anos de 1928 e 1937. O Landesgruppe foi dividido em grupos locais (Ortsgruppen) espalhados pelos estados da federação. Porém, a filiação ao NSDAP era somente para os cidadãos alemães residentes no exterior, fato este que deixou de fora os descendentes de alemães nascidos no Brasil. Segundo Lucas, a adesão formal ao NSDAP foi ínfima, 1 em cada 26, um percentual de $3,87 \%$, entre 75 mil pessoas.

Ainda no capítulo de Lucas, o primeiro grupo local do NSDAP no Brasil foi fundado em 1928, no município de Timbó, em Santa Catarina. Os primeiros militantes nazistas no país eram agressivos e despertaram grande antipatia. Embora o NSDAP, dentro e fora da Alemanha, adotasse o "princípio de liderança”, nem sempre as diretrizes e as orientações de Berlim, através da $A O$, foram seguidas pelos seus militantes residentes no Brasil. Durante seus nove anos de existência, o Landesgruppen Brasilien promoveu diversas atividades de propaganda do Nazismo e do regime nacional-socialista, especialmente entre as comunidades de origem alemã localizadas nas regiões Sudeste e Sul do país.

\footnotetext{
${ }^{1}$ Doravante, identificado através da sigla NSDAP, do alemão Nationalsozialistische Deutsche Arbeiterpartei.
} 
Além disso, seus militantes mantiveram relações ambíguas e complexas com a Ação Integralista Brasileira - AIB, o poder público e a Igreja Luterana.

No Brasil, a propaganda nazista foi veiculada através de diferentes tipos de publicações impressas, a exemplo do guia oficial da Semana Alemã de 1937, na cidade de Curitiba, cujos textos foram organizados pelo grupo local do NSDAP. Em seu capítulo, Vinícius Liebel examinou essa publicação, na qual constatou a veiculação de propaganda nazista através de escritos sobre "raça", "sangue" e outros conceitos relevantes para ideologia nacional-socialista.

Outro alvo da propaganda nazista nas regiões de colonização alemã foram as “escolas alemãs". Segundo o estudo feito por Priscila Perazzo e Mariana Lins Padro, durante a década de 1930, as escolas alemãs localizadas na microrregião do ABC Paulista foram abastecidas de brochuras, livros, partituras e panfletos nazificados, destinados a alunos, pais e professores.

Ao estudar as relações entre os militantes nazistas e a AIB no Paraná, Rafael Athaides explica que, até o fim da década de 1930, em um contexto de aproximação diplomática e econômica entre Brasil e Alemanha, o NSDAP não foi incomodado pelo poder público. Inclusive, o então interventor federal no estado, Manoel Ribas (1873 1946), prestigiou celebrações nazistas, assim como outro interventor, Flores da Cunha (1880 - 1959), no Rio Grande do Sul. No tocante às relações com a AIB, Athaides (2018, p. 83) constatou a existência de "certas zonas de interface entre a NSDAP e a AIB". Porém, nada igual ao que foi denunciado pelos órgãos de segurança do regime estadonovista (1937-1945) como uma conspiração nazi-integralista, cujas denúncias foram recorrentes na imprensa brasileira da época.

Contudo, a situação do NSDAP, dos cidadãos alemães e das comunidades teutobrasileiras mudou radicalmente após a instalação do Estado Novo, em novembro de 1937. Governando como um autocrata, Getúlio Vargas outorgou uma Constituição nova e aboliu os partidos políticos no país, entre os quais o NSDAP. O desencadeamento da Campanha de Nacionalização, em 1938, o início da Segunda Guerra Mundial, em 1939, e a deterioração das relações diplomáticas entre Brasil e Alemanha transformaram alemães e teuto-brasileiros em nazistas, sendo considerados ameaças à segurança do país, 
especialmente, com base na retórica do "perigo alemão". Nesse contexto, instituições de origem alemã, a exemplo da Igreja Luterana, foram perseguidas pelas autoridades públicas civis e militares, conforme mostra o capítulo escrito por Sergio Luiz Marlow.

A obra é encerrada com dois capítulos que abordam alguns dos reflexos da experiência nazista no Brasil, a partir do pós-guerra. O primeiro, escrito por Bruno Leal Pastor de Carvalho, examina a repercussão na imprensa brasileira dos casos de criminosos de guerra do Eixo descobertos no Brasil, a exemplo de Herberts Cukurs (19001965). Já o segundo, de autoria de René Gertz, discute as formas com as quais comunidades de origem alemã no Rio Grande do Sul procuraram superar a associação ao Nazismo e as perseguições sofridas durante a Campanha de Nacionalização e a Segunda Guerra Mundial. Segundo Gertz, a partir do pós-guerra, foi iniciada uma operação de produção de memórias que valorizaram as contribuições dos imigrantes alemães para o país e de tentativas de apurar e punir os abusos cometidos pelas autoridades públicas riograndenses durante o período.

Os efeitos do Nazismo e da Segunda Guerra Mundial afetaram de forma incisiva as comunidades teuto-brasileiras do Rio Grande do Sul. Nessas comunidades, a cicatrização das feridas abertas durante as décadas de 1930 e 1940 ocorreu ao longo da segunda metade do século passado, tendo na memória e na história dois dos seus meios.

Ao encerrar uma conferência denominada "O Fascismo eterno", realizada nos Estados Unidos, em 1995, Umberto Eco (2018, p. 56-57) afirmou que, em nosso futuro, “desenha-se um populismo qualitativo de TV ou internet, no qual a resposta emocional de um grupo selecionado de cidadãos pode ser apresentada e aceita como a 'voz do povo'”, como nas experiências históricas da Itália (Fascismo) e da Alemanha (Nazismo). No Brasil contemporâneo, os "salvadores da pátria", o apelo à emoção e a hostilidade contra os intelectuais estão na ordem do dia, características estas que lembram os fascismos históricos.

Esta resenha não tem o objetivo de avaliar o risco do país em sofrer uma “fascistização”, embora o problema já faça parte do repertório de discussões acadêmicas em cursos universitários e periódicos, conforme sugere o artigo assinado por Eduardo Rebuá (2019). O livro Expressões do Nazismo no Brasil examina a experiência histórica do 
Nazismo em terras brasileiras durante a década de 1930 com inegável relevância historiográfica. Ademais, seus capítulos também contribuem para o entendimento do nosso tempo presente e os riscos que ele envolve. Afinal, como certa vez escreveu o historiador Caio Boschi (2004), estudamos a história para conhecer e transformar a vida, motivados pelas indagações e perplexidades do presente.

\section{Referências}

BOSCHI, Caio. História: por que e para quê? Nossa história, Rio de Janeiro, v. 1, n. 11, p. 98, set. 2004.

ECO, Umberto. O Fascismo eterno. Rio de Janeiro: Record, 2018.

EVANS, Richard J. Terceiro Reich na história e na memória: novas perspectivas sobre o nazismo, seu poder político, sua intrincada economia e seus efeitos na Alemanha do pósguerra. São Paulo: Crítica, 2018.

REBUÁ, Eduardo. Fascistização no Brasil do tempo-de-agora. Le Monde Diplomatique Brasil, São Paulo, v. 12, n. 138, p. 22-23, jan. 2019.

ROLLEMBERG, Denise. Revoluções de direita na Europa do Entre-guerras: o Fascismo e o Nazismo. Estudos históricos, Rio de Janeiro, v. 30, n. 61, p. 355 - 378, maio/ago. 2017.

SCHURSTER, Karl. A construção do inimigo judeu: uma análise da obra de Jeffrey Herf. Revista Tempo e Argumento, Florianópolis, v. 7, n.15, p. 256 - 261, maio/ago. 2015.

Universidade do Estado de Santa Catarina - UDESC Programa de Pós-Graduação em História - PPGH Revista Tempo e Argumento Volume 11 - Número 27 - Ano 2019 tempoeargumento@gmail.com 